\title{
Gene Expression of Chicken Gonads Is Sex- and Side-Specific
}

\author{
Jessica Scheider ${ }^{a}$ Fabian Afonso-Grunz ${ }^{b, c}$ Klaus Hoffmeier ${ }^{c}$ Ralf Horres ${ }^{b, c}$ \\ Florian Groher $^{c} \quad$ Lukas Rycak $^{c}$ Jörg Oehlmann ${ }^{\mathrm{a}}$ Peter Winter ${ }^{\mathrm{c}}$ \\ Institutes for ${ }^{\mathrm{a}}$ Ecology, Evolution and Diversity and ${ }^{\mathrm{b}}$ Molecular BioSciences, Goethe University \\ Frankfurt am Main, and ${ }^{\mathrm{C}} \mathrm{GenXPro} \mathrm{GmbH}$, Frankfurt/M., Germany
}

\section{Key Words}

Change of function - Chicken embryo - deepSuperSAGE . qRT-PCR · Sexual development · Stereology · Transcriptome

\begin{abstract}
In chicken, the left and right female gonads undergo a completely different program during development. To learn more about the molecular factors underlying side-specific development and to identify potential sex-and side-specific genes in developing gonads, we separately performed nextgeneration sequencing-based deepSuperSAGE transcription profiling from left and right, female and male gonads of 19-day-old chicken embryos. A total of 836 transcript variants were significantly differentially expressed $\left(p<10^{-5}\right)$ between combined male and female gonads. Left-right comparison revealed 1,056 and 822 differentially $\left(p<10^{-5}\right)$ expressed transcript variants for male and female gonads, respectively, of which 72 are side-specific in both sexes. At least some of these may represent key players for lateral development in birds. Additionally, several genes with laterally differential expression in the ovaries seem to determine female gonads for growth or regression, whereas right-left differences in testes are mostly limited to the differentially expressed genes present in both sexes. With a few exceptions,
\end{abstract}

side-specific genes are not located on the sex chromosomes. The large differences in lateral gene expression in the ovaries in almost all metabolic pathways suggest that the regressing right gonad might have undergone a change of function during evolution.

(c) 2014 S. Karger AG, Basel

Many mechanisms of avian sex determination are still unknown. Although sex in birds and mammals is genetically determined, the mammalian and avian sex chromosomes are not homologous [Fridolfsson et al., 1998]. In contrast to mammals, female birds are heterogametic (ZW), while males are homogametic (ZZ). It is not clear whether it is the presence of the $\mathrm{W}$ chromosome in females, the double representation of the $\mathrm{Z}$ chromosome in males vis-à-vis females, or both of these characteristics that are crucial for the determination of sex in birds [E]legren, 2000].

In every gonochoristic species, genetic pathways are differentially activated in males and females in order to initiate testis or ovary development [Merchant-Larios and Moreno-Mendoza, 2001; Ayers et al., 2013]. These sex-biased genes are often linked to reproduction, rendering many of them subject not only to natural selection

\section{KARGER}

E-Mail karger@karger.com

www.karger.com/sxd
(C) 2014 S. Karger AG, Basel

1661-5425/14/0084-0178\$39.50/0 
but as well to the pressures of sexual [Civetta and Singh, 1999; Swanson and Vacquier, 2002] and anthropogenic selection (e.g. hormone-mimicking chemicals in food and environment). Sex-biased gene expression is relatively common in metazoans [Ranz et al., 2003; Marinotti et al., 2006; Yang et al., 2006; Eads et al., 2007] and has important evolutionary [Meiklejohn et al., 2003; Zhang et al., 2004; Ellegren and Parsch, 2007; Mank et al., 2007], medical [Ivakine et al., 2005; Lu et al., 2007; Xu et al., 2008], and genomic implications [Connallon and Knowles, 2005, 2007; Hambuch and Parsch, 2005]. Strong right-left differences in females, however, are restricted to birds - except for birds of prey [Jacob and Bakst, 2007] - and characterized by a regressing right ovary with a medulla only, while the left one develops ongoing from day 7 of incubation to a functional ovary with cortex and medulla [Ukeshima and Fujimoto, 1991; Ukeshima, 1996; Smith, 2007; González-Morán, 2011]. Previous studies on avian gonad development mainly focused on early embryonic events based on histological descriptions [González-Morán, 2011] or on mRNA expression profiles of a distinct subset of genes [Hoshino et al., 2005; Hudson et al., 2005a, b; Rodríguez-Léon et al., 2008; Carré et al., 2011] as e.g. those involved in steroidogenesis, paracrine signaling, transcription, and homeostasis [Yamamoto et al., 2003; Diaz et al., 2011]. PITX2 and RALDH2 were shown to be important for ovarian dimorphism in the chicken embryo [Rodríguez-Léon et al., 2008; Smith et al., 2008a]. However, the molecular consequences of this differential expression are far from being completely understood. At present, the publication of the chicken genome [Wicker et al., 2005] along with the advent of next-generation sequencing (NGS)-based genome-wide gene expression profiling techniques provides the opportunity to monitor the differential gene expression of developing chicken gonads and to infer common and diverted mechanisms of gonadal differentiation from these data.

DeepSuperSAGE, a genome-wide, open-architecture transcriptome profiling technique, is the adaptation of SuperSAGE [Matsumura et al., 2003] to NGS [Matsumura et al., 2010, 2011; Zawada et al., 2011]. For the generation of comprehensive transcription profiles, so-called SuperTAGs, originating from the $3^{\prime}$ end of a given cDNA, are sequenced in their millions and annotated to their respective genes in an according database [Matsumura et al., 2003, 2005]. These SuperTAGs contain sufficient information to reliably characterize the cDNA and thus the transcript they are derived from [Velculescu et al., 1995; Saha et al., 2002]. Contrary to microarrays, deepSuper-

Gene Expression of Chicken Gonads Is

Sex- and Side-Specific
SAGE due to its open-architecture is able to quantify the expression of virtually all polyadenylated RNAs, including previously unknown and lowly expressed ones as well as natural antisense transcripts and polyadenylated noncoding RNAs without prior knowledge of the respective sequences.

There is only rudimentary research regarding the female right gonad, since most of the research was done focusing on the left gonads of both sexes. The present study provides a comprehensive description not only of the sex but especially of the side-specific differential sexual development of male and female chicken gonads on the level of gene expression at embryonic day 19 (E19). We wanted to see if there is any difference in male rightleft gene expression in E19 and if there is any parallelism to the female gonads. Our genome-wide characterization of differences in the gene expression of mature gonads in an unprecedented depth represents an important step to a molecular characterization of side-specific gonadal development in birds and has implications beyond this taxon for other vertebrate classes, including mammals.

\section{Materials and Methods}

\section{Gonad Tissue Isolation}

Newly laid fertile chicken eggs (White Leghorn, deriving from the same genetic background) were obtained from a commercial local supplier (LSL Rhein-Main, Schaafheim, Germany) and bred in a ThermoStar 100 egg incubator (J. Hemel Brutgeräte, Verl, Germany). Incubation was performed at $37.6^{\circ} \mathrm{C}$ and $60 \%$ humidity and egg turning once every $2 \mathrm{~h}$. On E19, 2 days before anticipated hatching, embryos were decapitated immediately after removal from the egg, dissected under a microscope, and sexed by gonad morphology.

\section{Genetic Sexing}

For genetic sex confirmation, blood samples from each embryo were collected in ethanol and stored at $-20^{\circ} \mathrm{C}$ till isolation of the DNA with the DNeasy (Qiagen, Hilden, Germany) isolation kit. Genetic sexing was carried out by a standard PCR protocol using the primers 2550F ( $5^{\prime}$-GTT ACT GAT TCG TCT ACG AGA-3') and 2718R (5'-ATT GAA ATG ATC CAG TGC TTG-3') previously described by Fridolfsson and Ellegren [1999]. These primers are focused on the CHD1 introns, placed on the Z (CHD1Z, 600 bp) and $\mathrm{W}$ chromosome (CHD1 W, $450 \mathrm{bp}$ ). Thermal cycling comprised DNA polymerase activation at $95^{\circ} \mathrm{C}$ for $1 \mathrm{~min}$ followed by 30 cycles of denaturation at $95^{\circ} \mathrm{C}$ for $30 \mathrm{~s}$, annealing at $52^{\circ} \mathrm{C}$ for $30 \mathrm{~s}$, elongation at $72^{\circ} \mathrm{C}$ for $1 \mathrm{~min}$, and a final extension step at $72^{\circ} \mathrm{C}$ for $3 \mathrm{~min}$. All amplifications were performed on an advanced primus 96 thermocycler (Peqlab, Erlangen, Germany). The amplicons of this modified protocol were separated into 1 band $(Z)$ in the case of male or 2 bands $(Z+W)$ in the case of female animals on a $1.4 \%$ agarose gel. 


\section{Total RNA Isolation}

Gonads were separated, cleaned from adhesive tissue, and immediately frozen individually in $200 \mu \mathrm{l}$ RNA lysis buffer (Promega, Mannheim, Germany) for later RNA isolation. Total RNA was extracted using the SV Total RNA Isolation System Kit according to manual 048 (Promega). Deviating from the protocol, on-column DNaseI digestion of genomic DNA was elongated from original 15 min to $30 \mathrm{~min}$. Additionally, DNaseI digestion was carried out with Baseline-Zero ${ }^{\mathrm{TM}}$ DNase (Epicentre; provided by Biozym Scientific GmbH, Hessisch Oldendorf, Germany) in solution to ensure that the samples were completely free of DNA. Total RNA concentration was estimated in a dilution series with the LabelGuard NanoPhotometer (Implen, München, Germany). RNA quality and quantity was further determined using a Caliper labon-a-chip system (Agilent, Hopkinton, Mass., USA). All isolated total RNA samples had an RNA Integrity Number (RIN) ranging from $8.5-10.0$ (highest quality).

\section{Library Preparation and Bioinformatics}

DeepSuperSAGE libraries were constructed from total RNA of gonads from 10 pooled individuals by GenXPro GmbH essentially as described previously [Matsumura et al., 2010, 2011; Zawada et al., 2012] with slight modifications. Sequencing was performed on Illumina's Genome Analyzer IIx, and subsequent base calling was carried out by Illumina's GAPipeline v1.0. Distinct libraries were sorted out from the bulked sequencing data according to their respective indices, followed by elimination of PCR-derived tags identified by TrueQuant technology (GenXPro). The 26-bp SuperTAGs were extracted from the remaining sequences, counted, and subsequently combined to TAG groups of common origin (UniTAGs) according to Akmaev and Wang [2004]. For each library, the UniTAG read numbers were normalized to a million sequenced reads in total (tags per million; TPM) to establish comparability. The UniTAG numbers of the pooled datasets from left and right gonads were generated by in silico calculation of the arithmetic mean of the normalized read counts from the left and right gonad in the respective libraries. Logarithmic fold changes (base 2) were determined by pair-wise comparison of the normalized UniTAG numbers in the particular libraries, and statistical significance was assessed by $\chi^{2}$ tests according to Man et al. [2000]. If a given UniTAG was only present in 1 of the 2 libraries, the respective TPM count was adjusted from 0 to 0.05 to allow for calculation of fold changes.

\section{Annotation of SuperTAGs}

The UniTAG reads were annotated in a multi-step procedure using the BLAST software [Altschul et al., 1997] to ensure an unambiguous assignment to their corresponding transcripts and to eliminate any remaining adaptor sequences. Reference datasets were extracted from the publicly accessible databases at the Harvard University (HU; ftp://occams.dfci.harvard.edu/pub/bio/tgi/ data/Gallus_gallus) and the National Center for Biotechnology Information (NCBI; ftp://ftp.ncbi.nih.gov/refseq/release/vertebrate_other). A third reference comprising only sequences from Gallus gallus was generated based on the above-mentioned NCBI dataset, and finally, all 3 databases were trimmed to generate subsets (26-bp references) that only comprise sequences from the last possible anchoring site for a given SuperTAG. Beginning with a minimum required BLAST score of 52, UniTAG reads were successively aligned against these reference datasets in the following order of precedence: (1) 26-bp HU dataset, (2) 26-bp NCBI subset of G. gallus, (3) full-length HU, and (4) full-length NCBI subset. Reads which did not attain the specified BLAST score were reannotated in the same fashion with a lowered required score of 48 , and in a third round of 44 . Still not annotated reads were finally also aligned against the complete NCBI dataset with a required BLAST score of 42 or above. In this final annotation step, the complete 26-bp NCBI dataset was used as the third reference, followed by the full-length HU and G. gallus NCBI reference and the complete full-length NCBI dataset as final reference. UniTAG reads, which could not be annotated with this multi-step procedure, were excluded from further analysis.

\section{Validation of deepSuperSAGE Results with Selected \\ Transcripts}

For comparison of the tendencies in gene expression of both datasets (deepSuperSAGE vs. qRT-PCR), $\log _{2}$ fold changes were calculated with the TPM values of the respective UniTAGs and compared to the qPCR-based fold change (fig. 1). The quantitative real-time PCR assays (TaqMan/dual labeled probe qPCR assays) were performed on transcripts previously selected according to their differential expression profile in the sequencing data. Total RNA isolations of additional tissues were performed as described above. The primer assays for this study were designed and provided by GenXPro GmbH. Quantitative real-time PCR reactions were run as a one-step qPCR (Applied BioSystems StepOne RTPCR systems) with dual labeled probes (FAM-BHQ) and ROX reference dye (Invitrogen, Darmstadt, Germany) as passive reference. An amount of $5 \mathrm{ng}$ of total RNA served as template for each reaction of $15 \mu \mathrm{l}$. The applied One-Step RT-PCR Mastermix (Clontech-Takara QTaq-Mastermix) contained hot start Taq DNA polymerase, an optimized reaction buffer, $5 \mathrm{mM} \mathrm{MgCl}_{2}$ (final concentration), 2.5-3.5 mM nucleotides (including $200 \mu \mathrm{M}$ dUTP), and a reverse transcriptase combined with an RNase inhibitor. Specific primers were applied with a final concentration of $0.2-1.0$ $\mu \mathrm{M}$, and the dual labeled probes of $0.016-0.08 \mu \mathrm{M}$. The PCR regime consisted of the following steps: (1) reverse transcription: $48^{\circ} \mathrm{C}$ for $20 \mathrm{~min}$; (2) activation of the hot start Taq DNA polymerase (inhibited by antibody during reverse transcription) at $95^{\circ} \mathrm{C}$ for $10 \mathrm{~min}$, and (3) 45 cycles with denaturing at $95^{\circ} \mathrm{C}$ for $15 \mathrm{~s}$, and an annealing/ extension step at $60^{\circ} \mathrm{C}$ for $1 \mathrm{~min}$.

Amplification of the target genes was monitored by qPCR probe-released fluorescence (FAM dye) at each cycle. The threshold cycle $\left(\mathrm{C}_{\mathrm{t}}\right)$, defined as the PCR cycle at which a statistically significant increase of reporter fluorescence is first detected $(10 \times$ above background), was used as a measure for the starting copy numbers of the respective gene. Relative quantification of the amplified targets was performed via the comparative $\Delta \Delta \mathrm{C}_{\mathrm{t}}$ method [Pfaffl, 2001]. The amount of target, normalized to an endogenous reference (AURKAIP1) and relative to the passive reference, is given by $2^{-\Delta \Delta \mathrm{C}_{\mathrm{t}}}$.

\section{Assignment of Transcription Profiles to Gene Ontology}

Categories

Though deepSuperSAGE and other modern transcriptome analysis technologies nowadays provide in-depth descriptions of gene expression, the assignment of a function to differentially expressed genes is not trivial in organisms that are not as comprehensively characterized as human and mice or rats. When there is no direct experimental evidence available, the most efficient way 


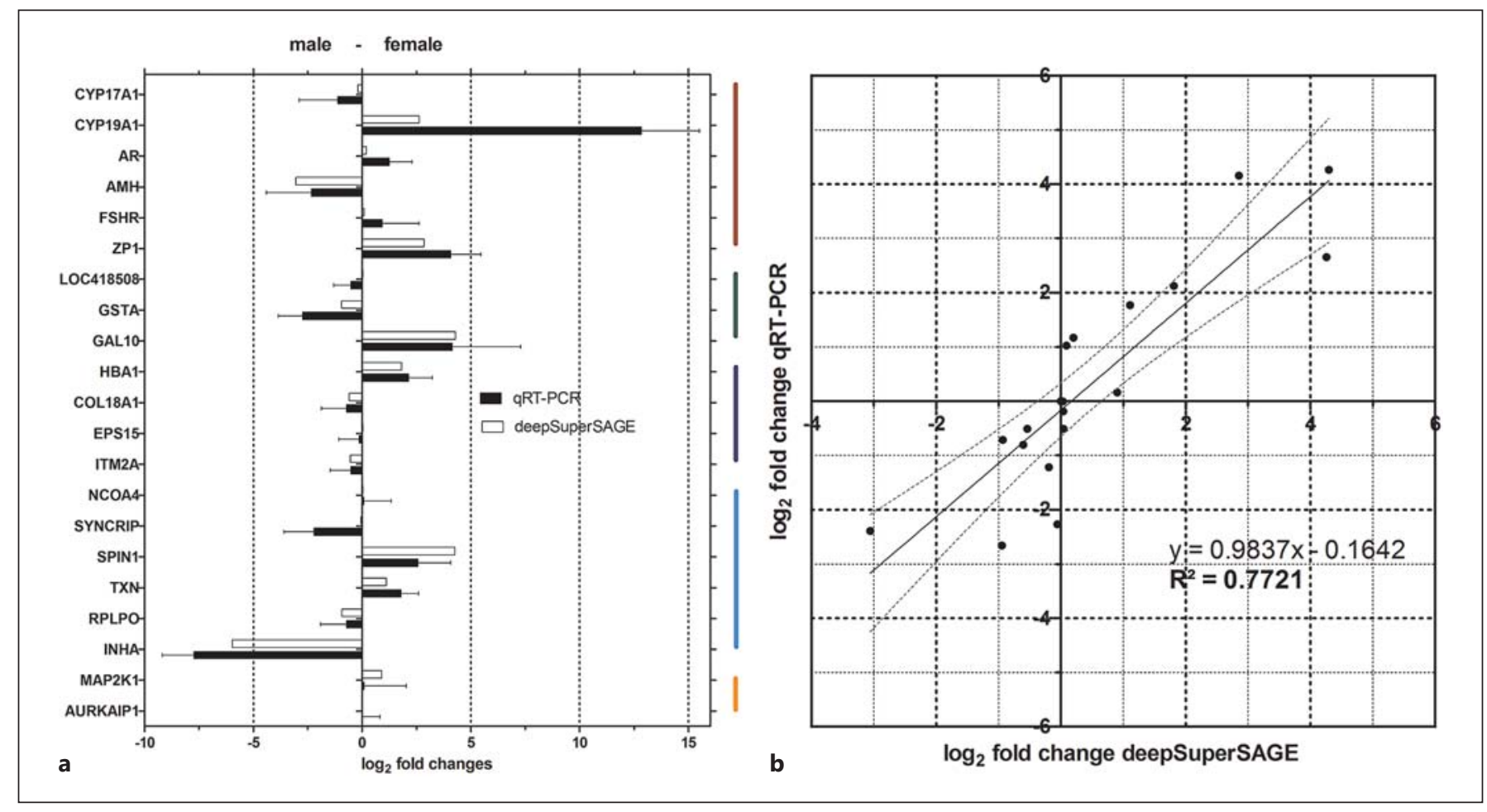

Fig. 1. Fold changes qRT-PCR/SuperSAGE. a Illustration of the $\log _{2}$ fold changes (male vs. female) from transcripts quantified by qRT-PCR and deepSuperSAGE. The qRT-PCR fold changes are derived from 5 male and 6 female individual gonads (right and left) with 3 replicates each. DeepSuperSAGE values were acquired with 10 pooled male and female gonads (right and left). Nomenclature was taken from NCBI. Color code identifies metabolic pathways; red $=$ sexual differentiation, green $=$ defense/immune reactivity, dark blue $=$ blood, light blue $=$ transcription factors $/$ cofactors $/$ ribosome/nuclei, orange $=$ kinases. $\mathbf{b}$ Correlation between the $\log _{2}$ fold changes (male vs. female) derived from qRT-PCR and deepSuperSAGE (transformed with the equation $\mathrm{x}^{(1 / \mathrm{x})}$ ) calculated by linear regression $\left(R^{2}=0.77\right)$. Individuals are the same as in $\mathbf{a}$. of function assigning is based on strict orthology, one of the central concepts of comparative genome analysis. By definition, orthologs are genes or proteins in 2 or more species that share significant similarity and that are thought to have diverged from a common ancestral gene that existed in their last common ancestor [Remm et al., 2001; Li et al., 2003; O'Brien et al., 2004; Chen et al., 2006; Hulsen et al., 2006]. Determination of orthology relations facilitates the knowledge transfer between species and can be used to improve both structural and functional annotation in organisms that are less well annotated. At present, there are several ortholog prediction methods and search tools available [O'Brien et al., 2005; Wright et al., 2005; Li et al., 2006; Hubbard et al., 2007]. However, the number of proteins from one species that is considered to be part of the same orthologous group in another species varies from one method to another due to differently employed algorithms and the diversity of species included in these methods [Hulsen et al., 2006]. Since most gene ontology (GO) annotations for newly sequenced species provided by the EBIGOA Project [Camon et al., 2004] are based on Electric Annotation (IEA) that is not assigned by a curator, these annotations do not necessarily include the gene products determined by deepSuperSAGE. Here, we used IEAbased GO (http://www.geneontology.org/) to categorize differen- tially expressed genes and to assign a potential function to them. The final data set containing information from all the libraries was subjected to GO enrichment analysis using the GenXPro inhouse pipeline system.

\section{Data Accessibility}

The original SuperTAG sequences from this project will be available at Genome Expression Omnibus (http://www.ncbi.nlm. nih.gov/geo).

\section{Results}

\section{Annotation of SuperTAGs and qRT-PCR Validation of Determined Expression Profiles}

For the description of gene expression profiles in the gonads, we created 4 deepSuperSAGE datasets with about 2 million 26-bp SuperTAGs each, based on the sequences from distinct pools of 10 individual right and left ovaries 
and testes, respectively. Table 1 summarizes all tags and transcripts in the 4 libraries used for analysis.

From all annotated SuperTAGs, a total of 67,848 tags revealed high homology hits (BLAST score $=52$ ) in 1 or more of the respective databases; 3,339 annotated tags were considered to be predicted by the respective databases and therefore excluded from further analysis.

The reliability and reproducibility of deepSuperSAGE data was tested via qRT-PCR analysis of a subset of 21 transcripts with similar and dissimilar expression between male and female gonads. In most cases, SuperTAG counts from the pooled gonads represented the mean of the $\Delta \Delta \mathrm{C}_{\mathrm{t}}$ values obtained for a given RNA from individual specimens. The overall similarity and the high correlation $\left(\mathrm{R}^{2}=0.77\right)$ between the tested individual qRT-PCR and pooled deepSuperSAGE expression ratios (fig. 1) demonstrates the exact quantification of transcript levels by deepSuperSAGE profiling.

\section{Sex-Specific and Right-Left Expression Profile}

The cumulated and normalized UniTAGs could be classified into 61,312 G. gallus-specific UniTAGs representing 48,079 UniTAGs with low abundance (0.13-10 tags per million), 6,075 UniTAGs of intermediate abundance (10-100 tags per million), and 1,216 highly abundant UniTAGs ( $>100$ tags per million). These abundance categories contain on average 78,10 , and $2 \%$ of the total number of UniTAGs, respectively (upon request, data can be provided by the author). A total of 836 UniTAGs was found to be differentially expressed (M-F, $\mathrm{p}<10^{-5}$ ) between male and female gonads, and a considerable number of UniTAGs were exclusively detected in either the male or female gonads; 114 significantly differentially expressed UniTAGs $\left(\mathrm{p}<10^{-5}\right)$ between the sexes showed more than a 2 -fold difference in gene expression. Of these, 40 were up- and 74 down-regulated in testes compared to ovaries. The UniTags found laterally differently expressed are shown in table 2 . The 20 most significantly regulated mRNAs between male and female gonads are summarized in table 3 which is an extract of table 2.

The list of transcripts up-regulated in male gonads mainly consists of ribosomal proteins and subunits, inhibin, CDH1-D, DMRT1, and SPARC as the most upregulated mRNA in testes as compared to ovaries. SPARC (secreted protein acidic and rich in cysteine, originally described as osteonectin) is a highly conserved and abundant component of the extracellular matrix in bone tissues in vertebrate species [Termine et al., 1981; Bassuk et al., 1993]. SPARC binds to collagen type I-V in a calcium-
Table 1. SuperTAG and Gallus gallus-specific UniTAG numbers of the sequenced libraries

\begin{tabular}{lrrrr}
\hline & \multicolumn{1}{l}{ MR } & \multicolumn{1}{l}{ ML } & \multicolumn{1}{l}{ FR } & \multicolumn{1}{l}{ FL } \\
\hline SuperTAGs & $1,236,514$ & 998,025 & $1,527,482$ & $1,181,158$ \\
UniTAGs & 43,339 & 42,253 & 49,691 & 42,852 \\
\hline
\end{tabular}

$\mathrm{MR}=$ Male right; $\mathrm{ML}=$ male left $\mathrm{FR}=$ female right; $\mathrm{FL}=\mathrm{fe}-$ male left gonads.

Table 2. Differentially expressed UniTAGs

\begin{tabular}{lllll}
\hline & MR & ML & FR & FL \\
\hline MR & $\mathbf{2 , 2 9 9}$ & & & \\
& & & & \\
ML & $\uparrow 139$ & $\mathbf{1 , 9 9 1}$ & & \\
& $\downarrow 136$ & & & \\
FR & $\uparrow 538$ & $\uparrow 328$ & $\mathbf{4 , 7 8 6}$ & \\
& $\downarrow 462$ & $\downarrow 264$ & & \\
FL & $\uparrow 444$ & $\uparrow 240$ & $\uparrow 206$ & $\mathbf{1 , 9 9 9}$ \\
& $\downarrow 372$ & $\downarrow 166$ & $\downarrow 163$ & \\
\hline
\end{tabular}

Table of differentially expressed transcripts (FCh stronger than $|1|$ and $\left.\mathrm{p}<10^{-10}\right)$. The numbers in bold represent UniTAGs exclusively expressed in the respective gonad. Pairwise comparison of the libraries takes the library on the ordinate to the base. Up-regulated UniTAGs are indicated by upward and down-regulated UniTAGs by downward arrows. Abbreviations are the same as in table 1.

dependent manner and is prominent in regions of tissue morphogenesis which correlates with its proposed function as a mediator of tissue remodeling [Sage et al., 1989; Wu et al., 1996; Delostrinos et al., 2006]. CDH1-D and its homologs are suggested to play a role in temporal and spatial regulation of the anaphase-promoting complex in and outside of the cell cycle in chicken embryos of stage E15-20 [Wan and Kirschner, 2001].

The female up-regulated transcripts comprise phosphatidylcholine 2-acylhydrolase precursor (PLA2G2E precursor), WPKCI, tetraspanin-8 (TSPAN8), gallinacin (GAL-9, GAL-10), and gastrotropin.

Further differentially expressed transcripts between sexes include galectin-2 (LGALS2), galectin-3TM1 (LGALS3-TM1), thrombomucin and its precursor, aromatase, GATA binding factor 2 and 5 (GATA2, GATA5), hRSPO1, tetraspanin-1 (TSPAN1), prolactin receptor precursor, truncated testis-specific box 1-B or box 1-less 
Table 3. The 20 most differentially expressed transcripts

\begin{tabular}{|c|c|c|c|c|c|c|c|c|}
\hline \multirow{2}{*}{$\begin{array}{l}\text { Description } \\
\text { Female up-regulated }\end{array}$} & \multicolumn{2}{|l|}{ Fch M-F } & \multicolumn{2}{|c|}{ Fch M-FL } & \multicolumn{2}{|c|}{ Fch ML-MR } & \multicolumn{2}{|c|}{ Fch FL-FR } \\
\hline & & & & & & & & \\
\hline PLA2G2E & -9.30 & $*$ & -10.28 & $* * * *$ & -4.90 & n.s. & 6.92 & $* * * *$ \\
\hline TSPAN8 & -9.14 & $*$ & -10.06 & $* * *$ & 3.57 & n.s. & 4.2 & $* *$ \\
\hline Gallinacin 10-pre & -4.32 & $* * * *$ & -3.29 & $* * * *$ & -1.21 & $*$ & -1.63 & $* * * *$ \\
\hline Ig-superfamily protein & -3.62 & $* * *$ & -2.08 & $* * * *$ & 0.83 & $*$ & -2.27 & $* * * *$ \\
\hline MGP-pre & -3.58 & $*$ & -3.74 & $* * * *$ & 0.23 & n.s. & 0.34 & $*$ \\
\hline WPKCI & -3.43 & $*$ & -3.19 & $* *$ & 2.46 & $*$ & -0.43 & $*$ \\
\hline Gastrotropin & -2.35 & $*$ & -3.33 & $* * * *$ & 0.00 & n.s. & 6.01 & $* * * *$ \\
\hline ELN-pre & -2.13 & $* *$ & -1.86 & $* * * *$ & -0.85 & $*$ & -0.49 & $*$ \\
\hline Hemoglobin subunit beta & -1.84 & $* *$ & -1.65 & $* * * *$ & -0.45 & $*$ & -0.36 & $*$ \\
\hline LOC 100858011 & -1.76 & $* *$ & -1.77 & $* * * *$ & 0.04 & n.s. & 0.02 & n.s. \\
\hline $\mathrm{TXN}$ & -1.30 & $* *$ & -0.87 & $* * * *$ & -0.35 & $*$ & -0.75 & $* * *$ \\
\hline \multicolumn{9}{|l|}{ Male up-regulated } \\
\hline RPLP0 & 1.00 & $*$ & 0.65 & $* *$ & -1.04 & $* *$ & 0.81 & $*$ \\
\hline PKM & 1.04 & $*$ & 0.77 & $*$ & -0.19 & n.s. & 0.58 & $*$ \\
\hline LAMB1 & 1.04 & $*$ & 1.08 & * & -0.25 & $*$ & -0.08 & n.s. \\
\hline RPL37 & 1.05 & $*$ & 0.72 & $*$ & -0.39 & $*$ & 0.77 & $*$ \\
\hline RPL17 & 1.08 & $* *$ & 0.84 & $* *$ & -0.47 & $*$ & 0.52 & $*$ \\
\hline RPS17L & 1.12 & $* *$ & 0.74 & $* *$ & -1.34 & $* * * *$ & 0.91 & $* *$ \\
\hline \multicolumn{9}{|l|}{ Receptor expression-enhancing } \\
\hline protein 5 & 1.17 & $*$ & 1.39 & $*$ & -0.79 & $*$ & -0.42 & $*$ \\
\hline INHA & 3.77 & $*$ & 3.97 & $*$ & -0.80 & $*$ & -0.37 & n.s. \\
\hline CDH1 & 5.43 & $*$ & 4.97 & $*$ & 0.27 & n.s. & 1.14 & n.s. \\
\hline SPARC & 10.97 & $*$ & 10.97 & $* *$ & 0.62 & $*$ & n.d. & n.d. \\
\hline
\end{tabular}

The annotated UniTAGs were screened for the most differentially expressed transcripts between sexes (malefemale: M-F) and sorted accordingly. Nomenclature was taken from NCBI and Chicken Gene Nomenclature Consortium, if not tendered.

$\mathrm{Fch}=\log _{2}$ fold change; n.s. = not significant; n.d. = not detected; - pre = precursor of the respective transcript; other abbreviations are the same as in table 1 . $^{*} \mathrm{p}<10^{-5} ;{ }^{* *} \mathrm{p}<10^{-100} ;{ }^{* * *} \mathrm{p}<10^{-200} ; * * * * \mathrm{p}<10^{-300}$.

prolactin receptor, $\mathrm{SOX} 9, \mathrm{AMH}$ and its precursor (fig. $2 b, c)$.

General right-left comparison revealed 1,056 and 822 right-left differentially $\left(\mathrm{Fch}>|1| ; \mathrm{p}<10^{-5}\right)$ expressed UniTAGs for male and female, respectively. Interestingly, 72 of these UniTAGs are right-left specific in both sexes, with relatively low differences or significance between the sexes. The ovaries display a comprehensive side-specific expression of genes, while differential expression in right and left testes is limited to genes that are found to be generally right-left differentially expressed in both sexes (fig. 2a; table 2, 3). Of these, chromogranin A, specifically androgen-regulated isoform 1 , androgen receptor-associated co, somatostatin precursor, followed by surfactant protein A precursor, and cytidine deaminase display the strongest fold changes, and might represent some of the key player genes involved not only in sexual differentiation but rather in lateral development in birds (fig. 2a).

At day E19, differential gene expression in left and right ovaries clearly reflects the tendency of female gonads for growth or regressing in size. Growth-promoting expression patterns comprise the transcripts of e.g. TSPAN1, TSPAN8, GIIEp, galectin-2, gastrotropin, and SOX9. Cytidine deaminase and carboxypeptidase $\mathrm{O}$ are almost exclusively expressed in the growing left ovary. The most up-regulated mRNAs in the regressed right ovary (compared to female left ovary and male testes) are thrombomucin/thrombomucin precursor and aromatase. These genes are not located on the $\mathrm{W}$ or $\mathrm{Z}$ chromosome, but since the gonads are already well developed at day E19, this is not to be expected. These genes seem to be involved in the growth of the left or regression of the 


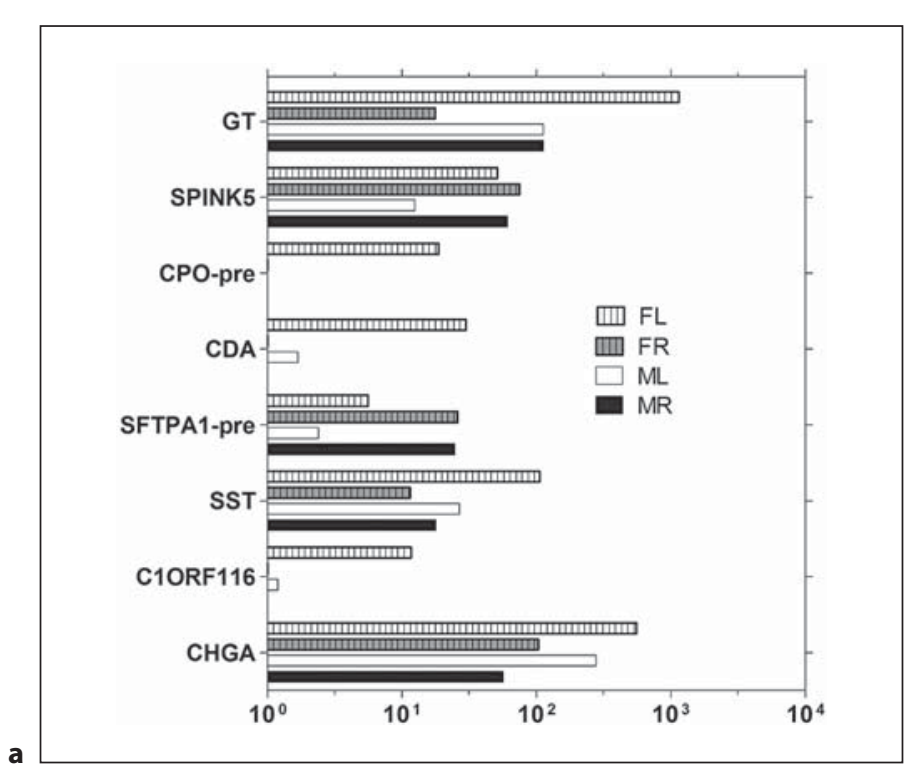

Fig. 2. Expression profiles of selected genes in distinct chicken E19 gonads. For graphical reasons, TPMs were transformed to $\log _{10}$ values. If less than 1 UniTAG per million sequenced tags was present, the respective TPM count was adjusted to 0 . The listed mRNAs are sorted for their most significant affiliation. Nomenclature was taken from NCBI and Chicken Gene Nomenclature Consortium if not indicated otherwise. - pre $=$ Precursor of the respective transcript; $\mathrm{MR}=$ male right; $\mathrm{ML}=$ male left; $\mathrm{FR}=$ female right; $\mathrm{FL}=$ female left. a Right-left differentially expressed mRNAs. b Female up-regulated mRNAs. c Male up-regulated mRNAs.

right female gonad, rather than in the differentiation of new tissues (fig. 2; table 3).

\section{Steroid Hormone Receptors}

The subfamily 3 of nuclear receptors includes steroid receptors as e.g. estrogen, glucocorticoid, progesterone, and androgen receptors as well as the estrogen receptorrelated receptors [Nuclear Receptors Nomenclature Committee, 1999; Germain et al., 2006]. Neither the estrogen, androgen, nor glucocorticoid receptors are differentially expressed between the sexes and between left and right gonads. Interestingly, the progesterone recep-
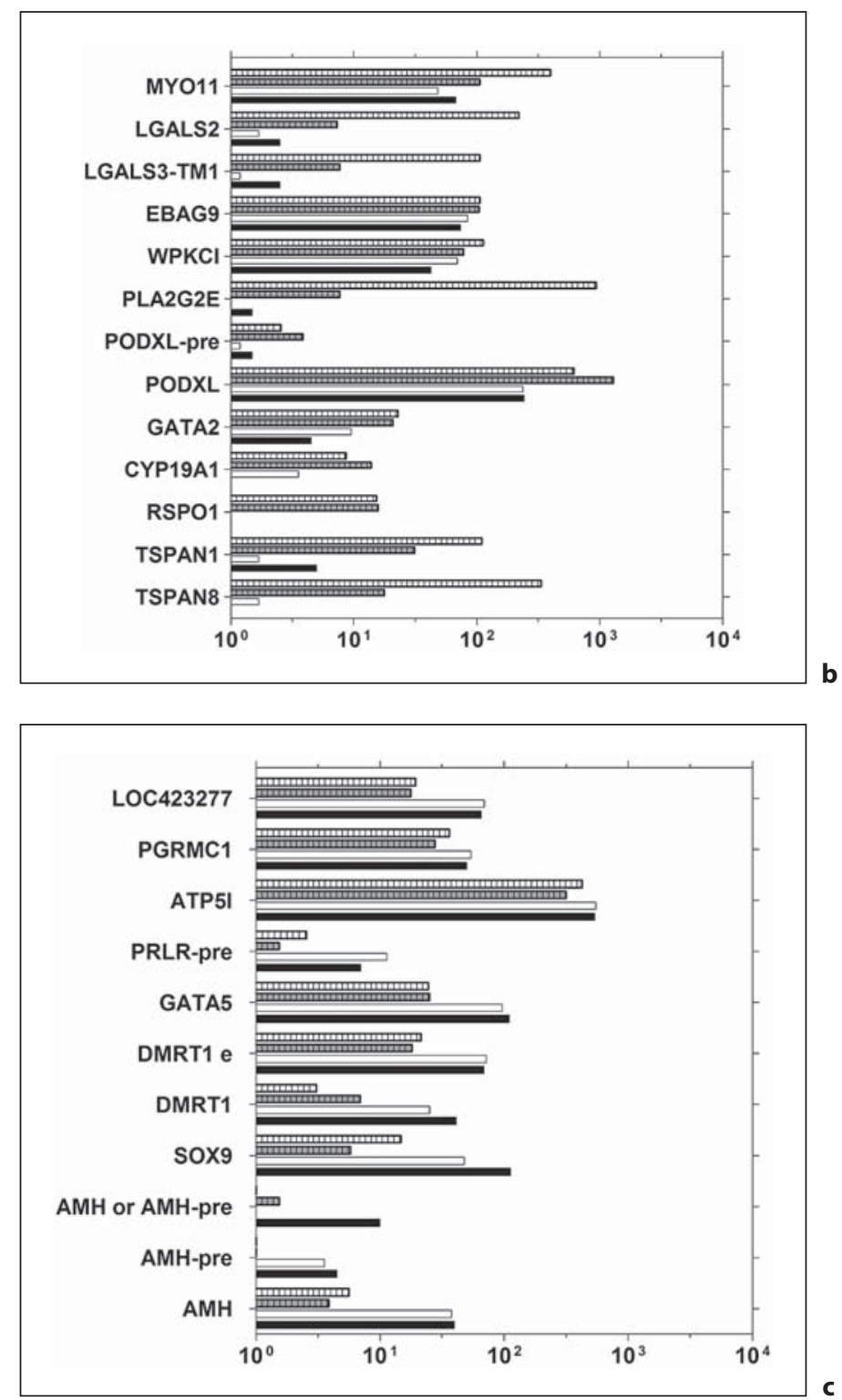

tor is slightly up-regulated in the female right gonad, while there is no significant difference between male gonads.

The mRNAs encoding steroidogenic enzymes required to convert cholesterol to androgens are already present in the avian embryo before gonadal differentiation [Nomura et al., 1999]. Besides significantly differential expression of P450arom and W-chromosome-based WPKCI transcripts as key players in the differentiation of gonads, we found the chicken orthologs of estrogen-related transcripts minimally differentially expressed between male and females, as e.g. estrogen receptor binding 
fragment associated gene 9 protein (EBAG9). The EBAG9 gene is conserved in human, chimpanzee, dog, cow, mouse, rat, and zebrafish. For most of the human EBAG9 counterparts, roles in ovarian or breast cancers have been described [Ikeda et al., 2000]. Their expression in chicken provides the opportunity to study their role in the development of sex-specific cancers in an easily accessible experimental system.

\section{Functional Annotation of Gene Expression}

The classification of transcripts from male and female gonads (M-F) into GO categories showed that 25,771 UniTAGs grouped to 'molecular function', 25,864 to 'cellular component', and 25,798 to 'biological process'. Differences in the abundance of tags in male and female gonads were considered significant at an enriched $\mathrm{p}<10^{-5}$. The most regulated GO:terms are listed in table 4 . The GO classification shows that the strongest $\left(\mathrm{p}<10^{-15}\right)$ differences occur in larval development (GO:0002164, up-regulated in left gonads of both sexes), nematode larval development (GO:0002119, up-regulated in left gonads of both sexes), and structuralconstituent of ribosome (GO:0003735, up-regulated in males). Additionally, the GO:terms postembryonic development (GO:0009791) and embryo development ending in birth or egg hatching (GO:00009792), both up-regulated in left gonads, are slightly lower significantly regulated than the development GO:terms.

Additionally, the GO:term growth (GO:0040007) is highly affected: it is up-regulated in females, especially in the growing left gonad. The good reliability of the presented data is proven by the fact that the affected GO:terms comprise different developmental stages from pre-hatching to post-hatching. This shows the validity of the identified transcription profiles: the embryonic development is nearly finished and the individual is shortly before hatching - 2 days left at E19.

\section{Discussion}

Since mammalian meiotic sex chromosome silencing [Turner, 2007] makes it difficult to investigate sexually antagonistic genes, birds are the model of choice for studying sex- and right-left biased gene expressions. The presented dataset gives the opportunity to analyze not only differential gene expression in females and males but above all lateral differences within a gender.

The fact that structural gonadal differentiation at day E19 is already very advanced in comparison to other surveys, though the left and right ovaries are still of almost

Gene Expression of Chicken Gonads Is

Sex- and Side-Specific similar size compared to mature gonads, has to be taken into account for a correct interpretation of the presented data. The maturation of gonads at E19 mainly involves growth or regression in size and not the development of new tissues. The chicken $\mathrm{Z}$ sex chromosome comprises over 700 known protein-coding and at least 45 non-coding genes (www.ensembl.org/Gallus_gallus). Any of these genes could play a role in sex determination and/or downstream of gonadal sex differentiation. The undifferentiated expression of these sex-determining genes at the already advanced stage of gonadal differentiation at E19 indicates that these mechanisms are not active anymore and explains the discrepancies between sex-chromosome-specific gene expression described in earlier developmental stages [McNagny et al., 1997; Carré et al., 2011] and our findings.

\section{Pluripotent Markers for Asymmetry Are}

Down-Regulated, Other Genes Have Taken the Wheel

Pluripotent markers like PITX2, Nanog, or PouV, found in other surveys especially in earlier stages [Ryan et al., 1998; Lavial et al., 2007; Intarapat and Stern, 2013] did not display an asymmetric expression in male or female gonads at E19. Additionally, neither Sox2 nor ERNI were found to be differentially expressed in the left or right gonads. All of them had been associated with asymmetric expression patterns in the gonads of both sexes by other authors in Hamburger-Hamilton $(\mathrm{HH})$ stages 33 and 35 [Hamburger and Hamilton; 1951]. Especially PouV, ERNI, and Nanog were reported to be less abundant in higher developmental stages [Lavial et al., 2007; Intarapat and Stern, 2013]. Our data confirm these findings for the above-mentioned genes for a speculation: the pluripotent genes lose importance in higher development stages, and other genes have taken the wheel, reacting to the status the pluripotent markers have predetermined.

In contrast to this, the germ cell marker $C v h$ as well as TP53 are both slightly up-regulated in the male left gonad. Cvh-expressing cells are present in the central zone of the area pellucida in $\mathrm{HH}$ stage 10, Cvh-positive cells were found in the hypoblast layer and anteriorly in the germinal crescent due to morphogenetic movement [Tsunekawa et al., 2000]. Cvh plays an essential role in germline formation, and $\mathrm{C} v h$-positive primordial germ cells have been located in the left gonads of both sexes in HH stage 35 [Intarapat and Stern, 2013]. TP53 belongs to a group of transport proteins carrying specific substances in the blood or across cell membranes. It is involved in cell cycle regulation as a trans-activator that negatively regulates cell division by controlling a set of genes required for this process. 
Table 4. The 15 most significantly affected GO:terms between sexes (M-F) and right and left gonads within sexes (FL-FR and ML-MR)

\begin{tabular}{|c|c|c|c|c|c|c|}
\hline & Identification (GO:term; GO level) & $\mathrm{TF}$ & reg & $\uparrow$ & $\downarrow$ & $\mathrm{p}$ \\
\hline \multirow[t]{18}{*}{$\mathrm{M}-\mathrm{F}$} & Molecular function $(0003647 ; 1)$ & 25,771 & & & & \\
\hline & structural constituent of ribosome $(0003735 ; 3)$ & 977 & 258 & 56 & 2 & $* * *$ \\
\hline & RNA binding $(0003723 ; 5)$ & 2,257 & 481 & 46 & 2 & $*$ \\
\hline & Cellular component $(0005575 ; 1)$ & 25,864 & & & & \\
\hline & mitochondrion $(0005739 ; 5,6)$ & 4,849 & 984 & 58 & 6 & $* *$ \\
\hline & ribosome $(0005840 ; 4,6)$ & 1,076 & 271 & 58 & 2 & $* *$ \\
\hline & cytosolic ribosome $(0022626 ; 5,6)$ & 738 & 200 & 52 & 2 & $* *$ \\
\hline & cytosol $(0005829 ; 5,6)$ & 4,215 & 856 & 71 & 14 & $* *$ \\
\hline & ribonucleoprotein complex $(0030529 ; 3,5)$ & 1,650 & 373 & 60 & 3 & $* *$ \\
\hline & cytosolic part $(0044445 ; 5,6)$ & 989 & 242 & 52 & 9 & $* *$ \\
\hline & Biological process $(0008150 ; 1)$ & 25,798 & & & & \\
\hline & nematode larval development $(0002119 ; 5,6)$ & 2,190 & 503 & 56 & 2 & $* * *$ \\
\hline & larval development $(0002164 ; 4,5)$ & 2,207 & 506 & 56 & 2 & $* * *$ \\
\hline & translation $(0006412 ; 6)$ & 1,841 & 429 & 62 & 6 & $* *$ \\
\hline & post-embryonic development $(0009791 ; 3,4)$ & 2,511 & 547 & 57 & 4 & $* *$ \\
\hline & embryo development ending in birth or egg hatching $(0009792 ; 5)$ & 4,189 & 847 & 67 & 7 & $* *$ \\
\hline & growth $(0040007 ; 2)$ & 4,211 & 845 & 65 & 6 & $* *$ \\
\hline & reproduction $(0000003 ; 2)$ & 4,669 & 926 & 75 & 8 & $* *$ \\
\hline \multirow[t]{17}{*}{ FL-FR } & Molecular function $(0003647 ; 1)$ & 25,771 & & & & \\
\hline & structural constituent of ribosome $(0003735 ; 3)$ & 977 & 341 & 52 & 4 & $* *$ \\
\hline & structural molecule activity $(0005198 ; 2)$ & 2,591 & 756 & 68 & 25 & * \\
\hline & Cellular component $(005575 ; 1)$ & 25,864 & & & & \\
\hline & ribosome $(0005840 ; 4,6)$ & 1,076 & 364 & 53 & 5 & $* *$ \\
\hline & cytosolic ribosome $(0022626 ; 5,6)$ & 738 & 264 & 46 & 5 & $* *$ \\
\hline & cytosol $(0005829 ; 5,6)$ & 4,215 & 1,202 & 77 & 23 & $* *$ \\
\hline & cytosolic part $(0044445 ; 5,6)$ & 989 & 326 & 48 & 12 & $* *$ \\
\hline & mitochondrion $(0005739 ; 5,6)$ & 4,849 & 1,347 & 77 & 20 & * \\
\hline & ribonucleoprotein complex $(0030529 ; 3,5)$ & 1,650 & 504 & 56 & 7 & * \\
\hline & Biological process $(0008150 ; 1)$ & 25,798 & & & & \\
\hline & translation $(0006412 ; 6)$ & 1,841 & 583 & 57 & 12 & $* *$ \\
\hline & larval development $(0002164 ; 4,5)$ & 2,207 & 674 & 56 & 8 & $* *$ \\
\hline & nematode larval development $(0002119 ; 5,6)$ & 2,190 & 669 & 55 & 8 & $* *$ \\
\hline & growth $(0040007 ; 2)$ & 4,211 & 1,185 & 74 & 16 & * \\
\hline & post-embryonic development $(0009791 ; 3,4)$ & 2,511 & 735 & 56 & 10 & * \\
\hline & embryo development ending in birth or egg hatching $(0009792 ; 5)$ & 4,189 & 1,171 & 67 & 21 & * \\
\hline \multirow[t]{18}{*}{ ML-MR } & Molecular function $(0003674 ; 1)$ & 25,771 & & & & \\
\hline & RNA binding $(0003723 ; 5)$ & 2,257 & 783 & 31 & 36 & * \\
\hline & structural molecule activity $(0005198 ; 2)$ & 2,591 & 877 & 36 & 42 & * \\
\hline & Cellular component $(0005575 ; 1)$ & 25,864 & & & & \\
\hline & mitochondrion $(0005739 ; 5,6)$ & 4,849 & 1,603 & 44 & 66 & $* *$ \\
\hline & plastid $(0009536 ; 5,6)$ & 898 & 340 & 13 & 16 & * \\
\hline & cytosolic part $(0044445 ; 5,6)$ & 989 & 363 & 23 & 31 & * \\
\hline & cytosolic ribosome $(0022626 ; 5,6)$ & 738 & 279 & 21 & 26 & * \\
\hline & Biological process $(0008150 ; 1)$ & 25,798 & & & & \\
\hline & larval development $(0002164 ; 4,5)$ & 2,207 & 816 & 30 & 48 & $* * *$ \\
\hline & nematode larval development $(0002119 ; 5,6)$ & 2,190 & 805 & 30 & 47 & $* * *$ \\
\hline & post-embryonic development $(0009791 ; 3,4)$ & 2,511 & 900 & 34 & 49 & $* *$ \\
\hline & growth $(0040007 ; 2)$ & 4,211 & 1,402 & 45 & 58 & $* *$ \\
\hline & translation $(0006412 ; 6)$ & 1,841 & 657 & 36 & 40 & $* *$ \\
\hline & translational elongation $(0006414 ; 6,7)$ & 163 & 84 & 2 & 7 & * \\
\hline & embryo development ending in birth or egg hatching $(0009792 ; 5)$ & 4,189 & 1,382 & 51 & 54 & * \\
\hline & reproduction $(0000003 ; 2)$ & 4,669 & 1,525 & 52 & 58 & * \\
\hline & embryo development $(0009790 ; 4)$ & 5,756 & 1,855 & 59 & 69 & * \\
\hline
\end{tabular}

$\mathrm{TF}=$ Transcripts found in the respective GO:term; reg = transcripts differentially regulated $\mathrm{p}<10^{-10} ; \uparrow=$ up-regulated transcripts; $\downarrow=$ down-regulated transcripts; $\mathrm{p}=$ enrichment $\mathrm{p}$ value; ${ }^{*} \mathrm{p}<10^{-5} ;{ }^{* *} \mathrm{p}<10^{-10} ;{ }^{* * *} \mathrm{p}<10^{-15}$. 
Another mRNA implicated in left-right asymmetry is $B M P 4$ which is slightly up-regulated in the left gonad of both sexes and significantly up-regulated in the female compared to male gonads. BMP4 is a bone morphogenetic protein that is a potent inducer of bone formation. BMPs belong to the TGF-beta family and negatively regulate the structure and function of the limb apical ectodermal ridge [Pizette and Niswander, 1999]. It is conceivable that this asymmetric expression relates to a similar function in gonadal development [Hoshino et al., 2005].

There are several other genes that are strongly up-regulated both in male and female left gonads (fig. 2a) and thus seem to be involved in later stages of side-specific development than the previously reported genes. Overexpression of genes in the right gonads is less prominent. The mRNAs encoding ovoinhibitor (serine peptidase inhibitor, Kazal type 5, SPINK5) and surfactant protein A, for instance, are only slightly up-regulated in male and female right gonads. These genes are not located on either of the sex chromosomes. Neither are the mRNAs almost exclusively expressed in the female left gonad as e.g. the tetraspanins TSPAN 1 and 8, PLA2G2E, LGALS2, and LGALS3-TM1 as well as somatostatin and myosin-11 (MYO11). TSPANs act as molecular facilitators and thus are involved in diverse processes. For example, proteins from the tetraspanin subfamily associate with integrin and support cell motility. Also, they have been ascribed a role in the development of the nervous system [Perron and Bixby, 1999]. PLA2G2E (GO:0004623) catalyzes the calcium-dependent hydrolysis of the 2 acyl groups in 3-sn-phosphoglycerides. LGALS2 (GO:0030246) and LGALS3-TM1 are interacting selectively and non-covalently with lactose and $\beta$-galactose, respectively. These genes are implicated in cell cycle regulation, and LGALS3 is furthermore involved in the mammalian endometrical system with a substantial role in uteral embryo implantation [Yang et al., 2012]. LGALS3 is also used as a tumor marker in mammals [Chiu et al., 2010; Righi et al., 2010]. Somatostatin acts as an inhibitor of growth hormone secretion [Florio et al., 1994]. Its functions include the modulation of neurotransmission, cell secretion, and cell proliferation [Patel, 1999]. None of the above mentioned genes - as many others differentially expressed between the sexes - is located on the $\mathrm{W}$ or $\mathrm{Z}$ chromosome which is to be expected in the advanced developmental stage of E19. Whether these differentially expressed genes have been (indirectly) activated by pluripotent markers or not warrants further research.

Gene Expression of Chicken Gonads Is

Sex- and Side-Specific

\section{High Usual Suspects Ratio}

We found a significantly higher expression of the Wlinked WPKCI gene (also known as HINTW or ASW) in embryonic ovaries than in testes. It is already expressed at E4.5 in the developing female gonads and has been suggested to be involved in avian sex determination [Hori et al., 2000; O'Neill et al., 2000; Smith and Sinclair, 2004]. Early WPKCI expression (E5) has also been detected in the avian spinal cord, spinal ganglion, and myotomes [Hori et al., 2000; Scholz et al., 2006]. The conserved vertebrate embryo gene DMRT1 is one of the mostly favored Z-linked candidate genes controlling gonadal sex differentiation [Nanda et al., 1999; Raymond et al., 1999; Smith et al., 2009; Chue and Smith, 2011], and our data confirms former observations [Shimada, 2002; Alam et al., 2008; Koba et al., 2008] that it is more expressed in testes versus ovaries. This is a further confirmation of the low effectiveness of dosage compensation of birds in higher developmental stages found in other surveys [Ellegren et al., 2007; Itoh et al., 2007]. The transcription profile generated via deepSuperSAGE allows for discrimination between DMRT1 and its isoform e. Interestingly, expression levels in the female left and right gonad differ severely, although both are generally more abundant in testes (fig. 2c). DMRT1 is about 1-fold up-regulated in the female right gonad compared to the left one, while its isoform e is more abundant in the female left gonad. The isoform e lacks the complete $3^{\prime}$ untranslated region from $D M R T 1$ which comprises several microRNA binding sites. The fact that DMRT1 isoform e is far more abundant in all tissues but lacking these microRNA binding sites leads to the speculation of a post-transcriptional regulation of the DMRT1 mRNA via microRNA-mediated degradation aside from alternative splicing mechanisms.

SOX9 is also found to be up-regulated in males, while RSPO1 as well as aromatase are up-regulated in females, concretizing the findings of Ayers et al. [2013] as well as Chue and Smith [2011]. DMRT1 has been suggested to activate the testicular marker SOX9 indirectly because of the time lag between DMRT1 and SOX9 expression (day 4.5 and day 6.5 of incubation, respectively), and the chicken homolog of hemogen ( $C H E M G N)$ was shown to link the expression of both [Nakata et al., 2013]. In line with this, we observed an exclusive expression of $c H E M G N$ in male gonads.

The secretion of $17 \beta$-estradiol in chicken E8 embryos is higher in the left ovary than in the right [Pedernera et al., 1999], and the higher amount of estrogen produced in the left ovary is suggested to protect the left Müllerian duct from the effects of anti-Müllerian hormone (AMH) [Vil- 

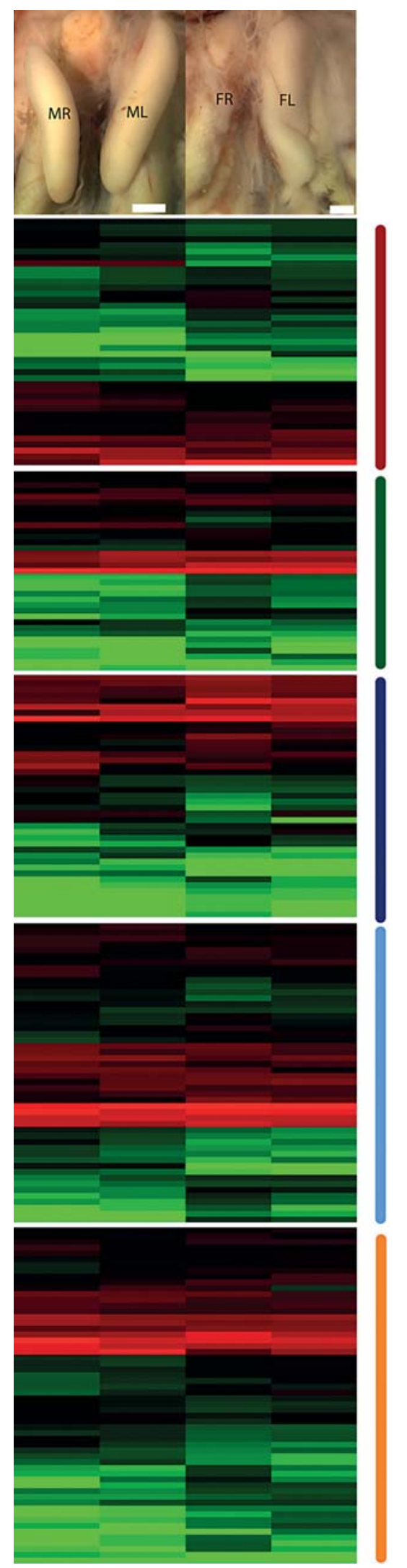

lalpando et al., 2000; Smith and Sinclair, 2001]. This is responsible for the regression of the right Müllerian duct in earlier stages [Oréal et al., 2002]. In our embryonic gonads, the AMH transcript is up-regulated in both male gonads compared to the females. Since males usually do not develop Müllerian ducts because of the elevated AMH level in early development stages, the up-regulation of $A M H$ in male gonads at E19 seems to have another - or additional - function. EBAG9 is the only mRNA related to estrogen that is slightly down-regulated in the male right gonad. The other estrogen receptors, in general, are not differentially expressed between the sexes. Additionally, we did not find any differential expression of WNT4 or $\beta$-catenin in our dataset which are both thought to be especially involved in ovary development [Chue and Smith, 2011; Ayers et al., 2013]. The most likely reason for the discrepancy between our and previous findings is that the ovaries are nearly finished in their structural differentiation at E19 compared to days E4.5-12.5 [Smith et al., 2008b].

\section{The Expression Profile of the Regressing Female Right}

\section{Gonad and Possible Implications}

Table 2 as well as the heat map in figure 3 both illustrate the differential expression of a selection of male and female as well as right-left differentially expressed genes. The male gonads in general do not display big differences in right-left comparisons. On the contrary, the regressing female right gonad exhibits strong differences in gene expression of transcripts involved in almost all metabolic pathways not only compared to left and right testes but also compared to the left ovary. Apart from genes involved in sexual development, also genes coding immune reactivity/defense/stress, blood building, as well as transcription factors and kinase transcripts show strong differences in male-female and, especially, right-left (female) gene expression.

Many strongly up-regulated genes in ovaries encode structural proteins (e.g. elastin, collagen, fibrilles), hemoglobin and - especially in the female right gonad - thrombomucin. This cell surface protein is distantly related to

Fig. 3. Heat map of the most differential male/female and right/left expressed genes. Photos of the gonads are displayed above the corresponding column, while selected, right-left differentially expressed genes from several metabolic pathways are shown in the heat map. Assignment of genes to metabolic pathways is based on the respective $\mathrm{GO}$ annotation, $\mathrm{p}_{\max }<9 \mathrm{E}^{-3}$. The color code indicates the same metabolic pathways as in figure 1 . Scale bar $=1 \mathrm{~mm}$. Abbreviations are the same as in table 1. 
CD34 and besides haemoglobin one of the most used human hematopoietic stem cell markers defining thrombocytes and multipotent hematopoietic progenitors [McNagny et al., 1997]. Surprisingly, our results seem to broaden the findings of McNagny et al. [1997] that this gene is highly expressed in female gonads. McNagny and co-workers stained early embryonic stages (E3-E5) and found that thrombomucin is mainly expressed on the surface of intra- and extraembryonic hematopoietic cells. Additionally, immune globulins, cytidine deaminase followed by carboxypeptidase $\mathrm{O}$ and defensins (Gal-10), as well as fibrinogen are also up-regulated in the ovaries. Our findings lead to the speculation that, within the scope of evolution, the rudimental right ovary might have gained new function(s) like e.g. hematopoiesis, because mucins have been shown to play both positive and negative roles in adhesion processes and thrombomucin may prevent the differentiation of hematopoietic cells [McNagny et al., 1997].

\section{Conclusions}

By application of deepSuperSAGE as a potent technique for the identification of differential gene expression in chicken E19 gonads, we identified several genes that seem to be more important for sexual and lateral develop- ment than previously thought. Some of these might be specific for the highly developed gonads in E19 and consequently may exert important functions in developed gonads. The presented dataset is an outstanding possibility for research in the field of right-left development, especially in view of gynandromorph animals [Zhao et al., 2010; Chue and Smith, 2011], and is going to assist studies on gene expression, especially in the context of comparative genomics. Our results will facilitate the study of evolutionarily important traits at the molecular level, deepening our knowledge of avian genomics, avian proteomics, endocrinology, as well as developmental biology, including sex differentiation.

\section{Acknowledgements}

The authors thank Ruth Jüngling and Anne Plöttner, University of Frankfurt, for technical advice, and Sabrina Giebner, University of Frankfurt, for assistance in preparation of the tissues as well as Nico Krezdorn, GenXPro, for handling of big datasets. We additionally thank 2 anonymous reviewers for very valuable advices.

This research was financially supported in the framework of Hessen ModellProjekte (HA project no. 155/08-11), financed with funds of LOEWE - Landes-Offensive zur Entwicklung Wissenschaftlich-ökonomischer Exzellenz, Förderlinie 3: KMU-Verbundvorhaben (State Offensive for the Development of Scientific and Economic Excellence).

\section{References}

Akmaev VR, Wang CJ: Correction of sequencebased artifacts in serial analysis of gene expression. Bioinformatics 20:1254-1263 (2004).

-Alam MA, Kobayashi Y, Horiguchi R, Hirai T, Nakamura M: Molecular cloning and quantitative expression of sexually dimorphic markers Dmrt1 and Foxl2 during female-to-male sex change in Epinephelus merra. Gen Comp Endocrinol 157:75-85 (2008).

-Altschul SF, Madden TL, Schäffer AA, Zhang J, Zhang Z, et al: Gapped blast and psi-blast: a new generation of protein database search programs. Nucleic Acids Res 25:3389-3402 (1997).

Ayers KL, Sinclair AH, Smith CA: The molecular genetics of ovarian differentiation in the avian model. Sex Dev 7:80-94 (2013).

Bassuk JA, Iruela-Arispe ML, Lane TF, Benson JM, Berg RA, Sage EH: Molecular analysis of chicken embryo SPARC (osteonectin). Eur J Biochem 218:117-127 (1993).

$>\mathrm{Ca}$
$>\mathrm{Ch}$
$>\mathrm{Ch}$
$>\mathrm{Ch}$

Camon E, Magrane M, Barrell D, Lee V, Dimmer E, et al: The gene ontology annotation (GOA) database: sharing knowledge in Uniprot with gene ontology. Nucleic Acids Res 32:D262D266 (2004).

Carré GA, Couty I, Hennequet-Antier C, Govoroun MS: Gene expression profiling reveals new potential players of gonad differentiation in the chicken embryo. PLoS One 6:e23959 (2011).

Chen F, Mackey AJ, Stoeckert CJ, Roos DS: OrthoMCL-DB: querying a comprehensive multi-species collection of ortholog groups. Nucleic Acids Res 34:D363-D368 (2006).

-Chiu CG, Strugnell SS, Griffith OL, Jones SJ, Gown AM, et al: Diagnostic utility of galectin-3 in thyroid cancer. Am J Pathol 176: 2067-2081 (2010).

Chue J, Smith CA: Sex determination and sexual differentiation in the avian model. FEBS J 278: 1027-1034 (2011).

Civetta A, Singh RS: Broad-sense sexual selection, sex gene pool evolution, and speciation. Genome 42:1033-1041 (1999).
Connallon T, Knowles LL: Intergenomic conflict revealed by patterns of sex-biased gene expression. Trends Genet 21:495-499 (2005).

Connallon T, Knowles LL: Recombination rate and protein evolution in yeast. BMC Evol Biol 7:235 (2007).

-Delostrinos CF, Hudson AE, Feng WC, Kosman J, Bassuk JA: The c-terminal $\mathrm{Ca}^{2+}$-binding domain of SPARC confers anti-spreading activity to human urothelial cells. J Cell Physiol 206:211-220 (2006).

Diaz FJ, Anthony K, Halfhill AN: Early avian follicular development is characterized by changes in transcripts involved in steroidogenesis, paracrine signaling and transcription. Mol Reprod Dev 78:212-223 (2011).

Eads BD, Colbourne JK, Bohuski E, Andrews J: Profiling sex-biased gene expression during parthenogenetic reproduction in Daphnia pulex. BMC Genomics 8:464 (2007).

Ellegren H: Evolution of the avian sex chromosomes and their role in sex determination. Trends Ecol Evol 15:188-192 (2000). 
Ellegren H, Parsch J: The evolution of sex-biased genes and sex-biased gene expression. Nat Rev Genet 8:689-698 (2007).

-Ellegren H, Hultin-Rosenberg L, Brunstrom B, Dencker L, Kultima K, Scholz B: Faced with inequality: chicken do not have a general dosage compensation of sex-linked genes. BMC Biol 5:40 (2007).

-Florio T, Rim C, Hershberger RE, Loda M, Stork PJ: The somatostatin receptor SSTR1 is coupled to phosphotyrosine phosphatase-activity in CHO-K1 cells. Mol Endocrinol 8:12891297 (1994).

Fridolfsson AK, Ellegren H: A simple and universal method for molecular sexing of non-ratite birds. J Avian Biol 30:116-121 (1999).

$\checkmark$ Fridolfsson AK, Cheng H, Copeland NG, Jenkins NA, Liu HC, et al: Evolution of the avian sex chromosomes from an ancestral pair of autosomes. Proc Natl Acad Sci USA 95:8147-8152 (1998).

- Germain P, Staels B, Dacquet C, Spedding M, Laudet V: Overview of nomenclature of nuclear receptors. Pharmacol Rev 58:685-704 (2006).

-González-Morán MG: Histological and stereological changes in growing and regressing chicken ovaries during development. Anat Rec 294:893-904 (2011).

Hambuch TM, Parsch J: Patterns of synonymous codon usage in Drosophila melanogaster genes with sex-biased expression. Genetics 170:1691-1700 (2005).

-Hamburger V, Hamilton HL: A series of normal stages in the development of the chick embryo. J Morphol 88:49-92 (1951).

- Hori T, Asakawa S, Itoh Y, Shimizu N, Mizuno S: Wpkci, encoding an altered form of PKCI, is conserved widely on the avian W chromosome and expressed in early female embryos: implication of its role in female sex determination. Mol Biol Cell 11:3645-3660 (2000).

Hoshino A, Koide M, Ono T, Yasugi S: Sex-specific and left-right asymmetric expression pattern of $B m p 7$ in the gonad of normal and sex-reversed chicken embryos. Dev Growth Differ 47:65-74 (2005).

-Hubbard TJ, Aken BL, Beal K, Ballester B, Caccamo M, et al: Ensembl 2007. Nucl Acids Res 35:D610-617 (2007).

Hudson QJ, Smith CA, Sinclair AH: Aromatase inhibition reduces expression of FOXL2 in the embryonic chicken ovary. Dev Dyn 233: 1052-1055 (2005a).

-Hudson QJ, Smith CA, Sinclair AH: Conserved expression of a novel gene during gonadal development. Dev Dyn 233:1083-1090 (2005b).

-Hulsen T, Huynen MA, de Vlieg J, Groenen PM: Benchmarking ortholog identification methods using functional genomics data. Genome Biol 7:R31 (2006).

Ikeda K, Sato M, Tsutsumi O, Tsuchiya F, Tsuneizumi M, et al: Promoter analysis and chromosomal mapping of human EBAG9 gene. Biochem Biophys Res Commun 273:654-660 (2000).
Intarapat S, Stern CD: Sexually dimorphic and sex-independent left-right asymmetries in chicken embryonic gonads. PLoS One 8:e69893 (2013).

Itoh Y, Melamed E, Yang X, Kampf K, Wang S, et al: Dosage compensation is less effective in birds than in mammals. J Biol 6:2-2 (2007).

Ivakine EA, Fox CJ, Paterson AD, Mortin-Toth SM, Canty A, et al: Sex-specific effect of insulin-dependent diabetes 4 on regulation of diabetes pathogenesis in the nonobese diabetic mouse. J Immunol 174:7129-7140 (2005).

Jacob M, Bakst MR: Anatomy of the female reproductive tract, in Jamieson BG (ed): Reproductive Biology and Phylogeny of Aves (Birds), vol 6A, pp 553-587 (USA: Science Publishers, Enfield 2007).

Koba N, Ohfuji T, Ha Y, Mizushima S, Tsukada A, et al: Profiles of mRNA expression of Foxl2, P450arom, Dmrt 1, Amh, P450(c17), Sf1, Er alpha and $A r$, in relation to gonadal sex differentiation in duck embryo. J Poultry Sci 45: 132-138 (2008).

Lavial F, Acloque H, Bertocchini F, MacLeod DJ, Boast S, et al: The Oct4 homologue Pouv and Nanog regulate pluripotency in chicken embryonic stem cells. Development 134:35493563 (2007).

Li H, Coghlan A, Ruan J, Coin LJ, Heriche JK, et al: Treefam: a curated database of phylogenetic trees of animal gene families. Nucleic Acids Res 34:D572-D580 (2006).

Li L, Stoeckert CJ, Roos DS: OrthoMCL: identification of ortholog groups for eukaryotic genomes. Genome Res 13:2178-2189 (2003).

Lu F, Bytautiene E, Tamayo E, Gamble P, Anderson GD, et al: Gender-specific effect of overexpression of $s F l t-1$ in pregnant mice on fetal programming of blood pressure in the offspring later in life. Am J Obstet Gynecol 197: 418 (2007).

Man MZ, Wang X, Wang Y: Power_sage: comparing statistical tests for sage experiments. Bioinformatics 16:953-959 (2000).

Mank JE, Hultin-Rosenberg L, Axelsson E, Ellegren H: Rapid evolution of female-biased, but not male-biased, genes expressed in the avian brain. Mol Biol Evol 24:2698-2706 (2007).

Marinotti O, Calvo E, Nguyen QK, Dissanayake S, Ribeiro JM, James AA: Genome-wide analysis of gene expression in adult Anopheles gambiae. Insect Mo Biol 15:1-12 (2006).

Matsumura H, Reich S, Ito A, Saitoh H, Kamoun $S$, et al: Gene expression analysis of plan host-pathogen interactions by superSAGE. Proc Natl Acad Sci USA 100:15718-15723 (2003).

Matsumura H, Ito A, Saitoh H, Winter P, Kahl G, et al: SuperSAGE. Cell Microbiol 7:11-18 (2005).

Matsumura H, Yoshida K, Luo SJ, Kimura E, Fujibe T, et al: High-throughput superSAGE for digital gene expression analysis of multiple samples using next generation sequencing. PLoS One 5:e12010 (2010).
Matsumura H, Yoshida K, Luo S, Krüger DH, Kahl G, et al: High-throughput superSAGE. Methods Mol Biol 687:135-146 (2011).

McNagny KM, Pettersson I, Rossi F, Flamme I, Shevchenko A, et al: Thrombomucin, a novel cell surface protein that defines thrombocytes and multipotent hematopoietic progenitors. J Cell Biol 138:1395-1407 (1997).

Meiklejohn CD, Parsch J, Ranz JM, Hartl DL: Rapid evolution of male-biased gene expression in Drosophila. Proc Natl Acad Sci USA 100:9894-9899 (2003).

Merchant-Larios H, Moreno-Mendoza N: Onset of sex differentiation: dialog between genes and cells. Arch Med Res 32:553-558 (2001).

$>$ Nakata T, Ishiguro M, Aduma N, Izumi H, Kuroiwa A: Chicken hemogen homolog is involved in the chicken-specific sex-determining mechanism. Proc Natl Acad Sci USA 110: 3417-3422 (2013).

Nanda I, Shan ZH, Schartl M, Burt DW, Koehler $\mathrm{M}$, et al: 300 million years of conserved synteny between chicken $\mathrm{Z}$ and human chromosome 9. Nat Genet 21:258-259 (1999).

Nomura O, Nakabayashi O, Nishimori K, Yasue $\mathrm{H}$, Mizuno S: Expression of five steroidogenic genes including aromatase gene at early developmental stages of chicken male and female embryos. J Steroid Biochem Mol Biol 71: 103-109 (1999).

Nuclear Receptors Nomenclature Committee: A unified nomenclature system for the nuclear receptor superfamily. Cell 97:161-163 (1999).

O'Brien KP, Westerlund I, Sonnhammer EL: Orthodisease: a database of human disease orthologs. Hum Mutat 24:112-119 (2004).

O’Brien KP, Remm M, Sonnhammer EL: Inparanoid: a comprehensive database of eukaryotic orthologs. Nucleic Acids Res33:D476-D480 (2005).

O'Neill M, Binder M, Smith C, Andrews J, Reed $\mathrm{K}$, et al: $A S W$ : a gene with conserved avian $\mathrm{W}$ linkage and female specific expression in chick embryonic gonad. Dev Genes Evol 210: 243-249 (2000).

Oréal E, Mazaud S, Picard JY, Magre S, CarreEusebe D: Different patterns of anti-mullerian hormone expression, as related to DMRT1, SF-1, WT1, GATA-4, Wnt-4, and Lhx9 expression, in the chick differentiating gonads. Dev Dyn 225:221-232 (2002).

Patel YC: Somatostatin and its receptor family. Front Neuroendocrinol 20:157-198 (1999).

Pedernera E, Solis L, Peralta I, Velazquez PN: Proliferative and steroidogenic effects of folliclestimulating hormone during chick embryo gonadal development. Gen Comp Endocrinol 116:213-220 (1999).

Perron JC, Bixby JL: Tetraspanins expressed in the embryonic chick nervous system. FEBS Lett 461:86-90 (1999).

Pfaffl MW: A new mathematical model for relative quantification in real-time RT-PCR. Nucleic Acids Res 29:e45 (2001). 
$\checkmark$ Pizette S, Niswander L: BMPs negatively regulate Smith CA, Sinclair AH: Sex determination in the structure and function of the limb apical ectodermal ridge. Development 126:883-894 (1999).

-Ranz JM, Castillo-Davis CI, Meiklejohn CD, Hartl DL: Sex-dependent gene expression and evolution of the Drosophila transcriptome. Science 300:1742-1745 (2003).

Raymond CS, Kettlewell JR, Hirsch B, Bardwell VJ, Zarkower D: Expression of Dmrt1 in the genital ridge of mouse and chicken embryos suggests a role in vertebrate sexual development. Dev Biol 215:208-220 (1999).

Remm M, Storm CEV, Sonnhammer ELL: Automatic clustering of orthologs and in-paralogs from pairwise species comparisons. J Mol Biol 314:1041-1052 (2001).

- Righi A, Jin L, Zhang S, Stilling G, Scheithauer BW, et al: Identification and consequences of galectin-3 expression in pituitary tumors. Mol Cell Endocrinol 326:8-14 (2010).

Rodríguez-Léon J, Esteban CR, Marti M, Santiago-Josefat B, Dubova I, et al: Pitx2 regulates gonad morphogenesis. Proc Natl Acad Sci USA 105:11242-11247 (2008)

Ryan AK, Blumberg B, Rodriguez-Esteban C, Yonei-Tamura $S$, Tamura $K$, et al: Pitx2 determines left-right asymmetry of internal organs in vertebrates. Nature 394:545-551 (1998).

- Sage H, Vernon RB, Funk SE, Everitt EA, Angello J: SPARC, a secreted protein associated with cellular proliferation, inhibits cell spreading in vitro and exhibits $\mathrm{Ca}^{2+}$-dependent binding to the extracellular-matrix. J Cell Biol 109: 341-356 (1989).

- Saha S, Sparks AB, Rago C, Akmaev V, Wang CJ, et al: Using the transcriptome to annotate the genome. Nat Biotechnol 20:508-512 (2002).

-Scholz B, Kultima K, Mattsson A, Axelsson J, Brunstrom B, et al: Sex-dependent gene expression in early brain development of chicken embryos. BMC Neurosci 7:12 (2006).

Shimada K: Sex determination and sex differentiation. Avian Poult Biol Rev 13:1-14 (2002).

Smith CA: Molecular genetics of avian, sex determination and gonadal differentiation, in Jamieson BG (ed): Reproductive Biology and Phylogeny of Birds, vol 6B, pp 479-506 (USA: Science Publishers, Enfield 2007). chicken embryo. J Exp Zool 290:691-699 (2001).

Smith CA, Sinclair AH: Sex determination: insights from the chicken. Bioessays 26:120132 (2004).

Smith CA, Roeszler KN, Bowles J, Koopman P, Sinclair AH: Onset of meiosis in the chicken embryo; evidence of a role for retinoic acid. BMC Dev Biol 8:85 (2008a).

-Smith CA, Shoemaker CM, Roeszler KN, Queen J, Crews D, Sinclair AH: Cloning and expression of R-spondin1 in different vertebrates suggests a conserved role in ovarian development. BMC Dev Biol 8:72 (2008b).

Smith CA, Roeszler KN, Ohnesorg T, Cummins DM, Farlie PG, et al: The avian Z-linked gene Dmrt1 is required for male sex determination in the chicken. Nature 461:267-271 (2009).

-Swanson WJ, Vacquier VD: The rapid evolution of reproductive proteins. Nat Rev Genet 3: 137-144 (2002).

Termine JD, Kleinman HK, Whitson SW, Conn KM, McGarvey ML, Martin GR: Osteonectin, a bone-specific protein linking mineral to collagen. Cell 26:99-105 (1981).

Tsunekawa N, Naito M, Sakai Y, Nishida T, Noce $\mathrm{T}$ : Isolation of chicken vasa homolog gene and tracing the origin of primordial germ cells. Development 127:2741-2750 (2000).

Turner JM: Meiotic sex chromosome inactivation. Development 134:1823-1831 (2007).

Ukeshima A: Germ cell death in the degenerating right ovary of the chick embryo. Zoolog Sci 13:559-563 (1996).

Ukeshima A, Fujimoto T: A fine morphological study of germ cells in asymmetrically developing right and left ovaries of the chick. Anat Rec 230:378-386 (1991).

-Velculescu V, Zhang L, Vogelstein B, Kinzler K: Serial analysis of gene expression. Science 270:484-487 (1995).

Villalpando I, Sanchez-Bringas G, Sanchez-Vargas I, Pedernera E, Villafan-Monroy H: The p450 aromatase (P450arom) gene is asymmetrically expressed in a critical period for gonadal sexual differentiation in the chick. Gen Comp Endocrinol 117:325-334 (2000).

-Wan Y, Kirschner MW: Identification of multiple $\mathrm{CDH} 1$ homologues in vertebrates conferring different substrate specificities. Proc Natl Acad Sci USA 98:13066-13071 (2001).
Wicker T, Robertson JS, Schulze SR, Feltus FA, Magrini V, et al: The repetitive landscape of the chicken genome. Genome Res 15:126-136 (2005).

Wright MW, Eyre TA, Lush MJ, Povey S, Bruford EA: HCOP: the HGNC comparison of orthology predictions search tool. Mamm Genome 16:827-828 (2005)

-Wu JX, Pines M, Gay CV, Hurwitz S, Leach RM: Immunolocalization of osteonectin in avian tibial dyschondroplastic cartilage. Dev Dyn 207:69-74 (1996).

Xu HY, Hou XW, Wang NF, Hui B, Jin JF, et al: Gender-specific effect of estrogen receptor-1 gene polymorphisms in coronary artery disease and its angiographic severity in Chinese population. Clin Chim Acta 395:130-133 (2008).

-Yamamoto I, Tsukada A, Saito N, Shimada K: Profiles of mRNA expression of genes related to sex differentiation of the gonads in the chicken embryo. Poultry Sci 82:1462-1467 (2003).

Yang H, Lei C, Zhang W: Expression of galectin-3 in mouse endometrium and its effect during embryo implantation. Reprod Biomed Online 24:116-122 (2012).

Yang X, Schadt EE, Wang S, Wang H, Arnold AP, et al: Tissue-specific expression and regulation of sexually dimorphic genes in mice. Genome Res 16:995-1004 (2006).

Zawada AM, Rogacev KS, Rotter B, Winter P, Marell R-R, Fliser D, Heine GH: Supersage evidence for CD14++CD16+ monocytes as a third monocyte subset. Blood (2011).

-Zawada AM, Rogacev KS, Hummel B, Grün OS, Friedrich A, et al: SuperTAG methylationspecific digital karyotyping reveals uremiainduced epigenetic dysregulation of atherosclerosis-related genes. Circ Cardiovas Genet 5:611-620 (2012).

Zhang Z, Hambuch TM, Parsch J: Molecular evolution of sex-biased genes in Drosophila. Mol Biol Evol 21:2130-2139 (2004).

Zhao D, McBride D, Nandi S, McQueen HA, McGrew MJ, et al: Somatic sex identity is cell autonomous in the chicken. Nature 464:237$242(2010)$.
Gene Expression of Chicken Gonads Is Sex- and Side-Specific 